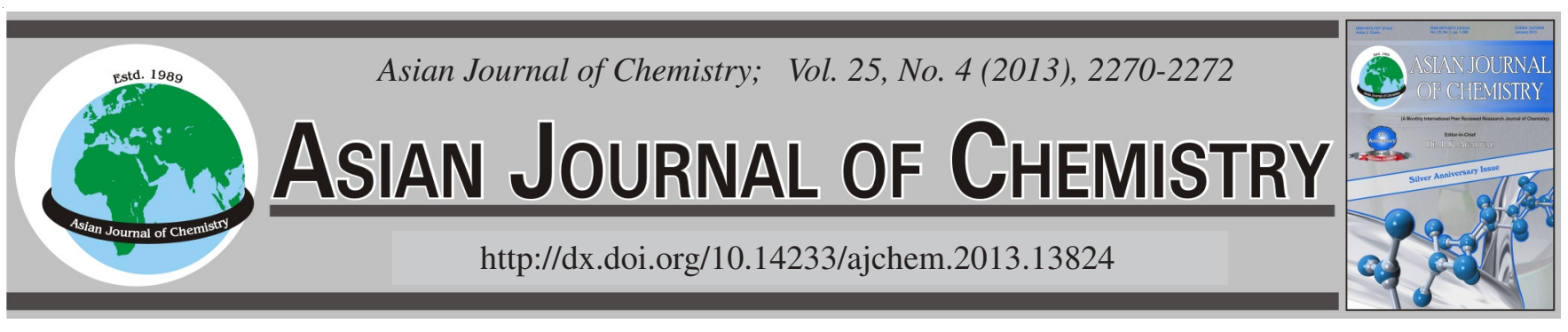

\title{
Spectrophotometric Determination of Manganese in Wine by Oxidizing Acid Fuchsin
}

\author{
Ying-Hong LiU ${ }^{1, *}$, Hong-wei Zhan ${ }^{2}$, Li-JuAn Heng ${ }^{1}$ and Wei-Xing MA ${ }^{1}$
}

${ }^{1}$ College of Chemical Engineering, Huaihai Institute of Technology, Lianyungang 222005, Jiangsu Province, P.R. China

${ }^{2}$ Jiangsu Lvyuan Engineering Design Research Co. Ltd, Lianyungang 222000, Jiangsu Province, P.R. China

*Corresponding author: Tel: +86 518 85857922; E-mail: liuyh9506@163.com; yinghong1978@yahoo.com.cn

(Received: 3 April 2012;

Accepted: 22 October 2012)

AJC-12328

\begin{abstract}
A new method was developed for the determination of manganese. The method is based on the oxidation of the reagent acid fuchsin by manganese(VII), which lead to the decoloration of the reagent. Determination of manganese was carried out by spectrophotometry after manganese with different valence being oxidized to $\mathrm{Mn}(\mathrm{VII})$ in the presence of sodium bismuth. Beer's law was obeyed from $0-1.3 \mu \mathrm{g} / \mathrm{mL}$ of $\mathrm{Mn}(\mathrm{VII})$ concentration with the apparent molar absorption coefficient of $2.52 \times 10^{4} \mathrm{~L} \mathrm{~mol}^{-1} \mathrm{~cm}^{-1}$. This method was satisfactorily used for the determination of trace manganese in wine samples.

Key Words: Acid fuchsin, Manganese, Spectrophotometry.
\end{abstract}

\section{INTRODUCTION}

Manganese is an essential trace element for human body, serving synthesis and activation of several enzymes including kineases, phosphatases and oxidoreductases. It also plays an important role in the brain ${ }^{1}$. However, excessive levels of this metal are harmful to the body, causing toxicity to the central nervous, respiratory, cardiac and reproductive systems ${ }^{2}$.

Various techniques have been utilized for manganese detection including X-ray fluorescence ${ }^{3}$, voltammetry ${ }^{4,5}$, atomic absorption spectrometry (AAS) ${ }^{6,7}$ and UV-VIS spectrophotometry ${ }^{8-10}$. Atomic absorption spectrometry is a technique widely used for quantification of manganese, but the apparatus used is more expensive than UV-VIS spectrophotometry. In this work, manganese is determined by VIS spectrophotometry, the method has advantages of low-cost, easy available chemicals and instrumentation, simple and direct application to real samples.

\section{EXPERIMENTAL}

A 722-N spectrophotometer (Shanghai precision \& Scientific instrument Co., Ltd., China) with matched $1 \mathrm{~cm}$ glass cells was used for all the spectrophotometric determination.

All chemicals were of analytical reagent grade and all the solutions were prepared with doubly distilled water. A manganese(VII) stock standard solution ( ca. $0.1 \mathrm{~g} \mathrm{~L}^{-1}$ ) was prepared by $\mathrm{KMnO}_{4}$ and calibrated by sodium oxalate. Working standard solutions were prepared by appropriate dilutions when required. Acid fuchsin solution $\left(0.1 \mathrm{~g} \mathrm{~L}^{-1}\right)$ and sulphate solution $\left(0.2 \mathrm{~mol} \mathrm{~L}^{-1}\right)$ were used.
Preparation for wine samples: $50 \mathrm{~mL}$ of wine samples were transferred into a $100 \mathrm{~mL}$ beaker and then heated to remove ethanol. The samples were nitrated by heating until there was no smoke volatilizing with $2 \mathrm{~mL}$ of concentrated sulphuric acid and $2 \mathrm{~mL}$ of concentrated nitric acid. After cooling, the solutions were transferred into a $50 \mathrm{~mL}$ volumetric flask and diluted to the marks with water.

Procedure: A suitable volume of Mn(VII) working solution was transferred into a $10 \mathrm{~mL}$ colorimetric tube with a glass stopper. Then, $1.5 \mathrm{~mL} \mathrm{H}_{2} \mathrm{SO}_{4}$ solution and $1.5 \mathrm{~mL}$ acid fuchsin solution were added. The solution was diluted to the mark with water and kept aside for $10 \mathrm{~min}$ at room temperature. The reagent blank solution which was absence of $\mathrm{Mn}$ (VII) was prepared as above. The absorbance a of the solution was measured at $550 \mathrm{~nm}$ with $1 \mathrm{~cm}$ cells by using reagent blank solution as reference.

\section{RESULTS AND DISCUSSION}

Absorption spectra: The absorption spectra of acid fuchsin and acid fuchsin-Mn(VII) mixture are shown in Fig. 1. It can be found that the addition of Mn(VII) to acid fuchsin makes the absorbance decrease and the maximum absorption wavelength does not change. The maximum absorbance difference is located at $550 \mathrm{~nm}$, so the wavelength is selected as determination wavelength.

Effect of acidity: Sulphate, nitrate and phosphate with same concentration were used as medium, respectively. The maximum absorbance occurs in sulphate medium from the results. The absorbance reach maximum and keep constant at 


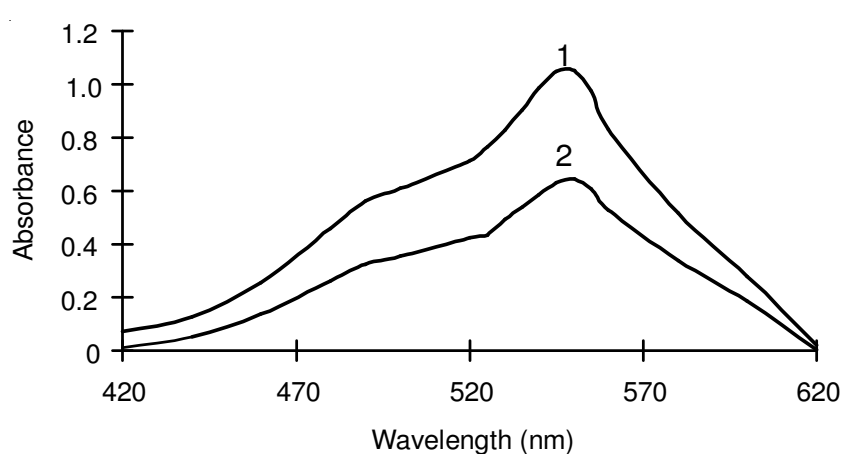

Fig. 1. Absorption spectra: $32 \mathrm{mg} \mathrm{L}^{-1}$ acid fuchsin, $1.5 \mu \mathrm{g} \mathrm{mL} \mathrm{m}^{-1} \mathrm{Mn}$ (VII), $0.03 \mathrm{~mol} \mathrm{~L}^{-1} \mathrm{H}_{2} \mathrm{SO}_{4}$. 1. acid fuchsin against water; 2. acid fuchsin and $\mathrm{Mn}(\mathrm{VII})$ against water

the sulphate concentration range of $0.01-0.03 \mathrm{~mol} \mathrm{~L}^{-1}$ (Fig. 2). So $0.03 \mathrm{~mol} \mathrm{~L}^{-1}$ sulphate was selected as reaction medium.

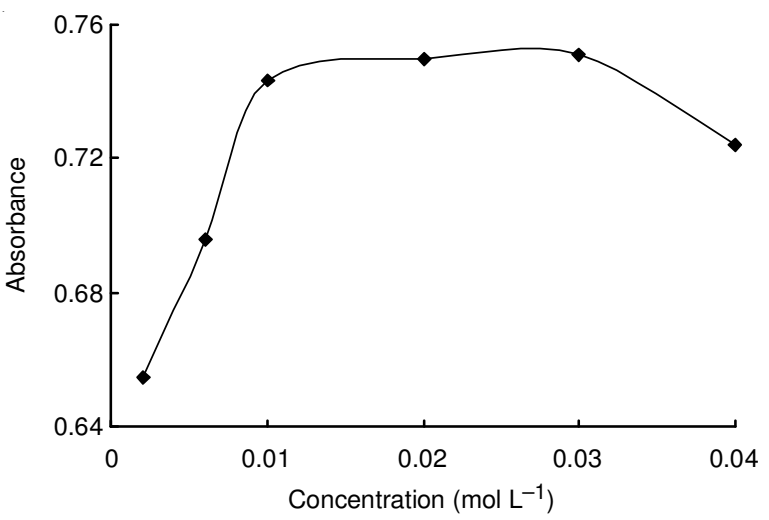

Fig. 2. Effect of sulphate concentration: $32 \mathrm{mg} \mathrm{L}^{-1}$ acid fuchsin, $1.5 \mu \mathrm{g} \mathrm{mL} \mathrm{m}^{-1}$ $\mathrm{Mn}(\mathrm{VII})$

Effect of acid fuchsin concentration: The effect of acid fuchsin solution concentration on the absorbance was explored and the results are shown in Fig. 3. It is obviously from the data that the absorbance is maximum and steady in the range of 1.0-2.0 mL. Therefore, $1.5 \mathrm{~mL}$ of acid fuchsin solution was used in this study.

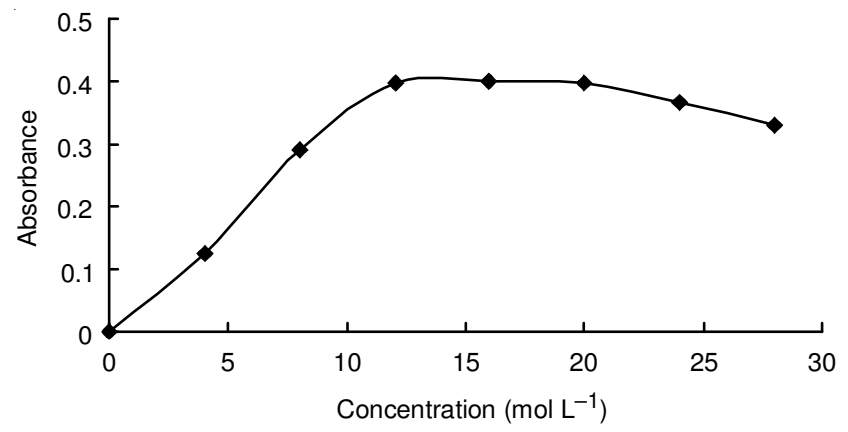

Fig. 3. Effect of acid fushin concentration: $1.0 \mu \mathrm{g} \mathrm{mL}^{-1} \mathrm{Mn}(\mathrm{VII}), 0.03 \mathrm{~mol}$ $\mathrm{L}^{-1} \mathrm{H}_{2} \mathrm{SO}_{4}$

Effect of reaction time and stabililty: The effect of reaction time was studied. As shown in Fig. 4, Mn(VII) reacts completely with acid fuchsin within $7 \mathrm{~min}$ at room temperature. The reaction product remains steady at least $2 \mathrm{~h}$.

Effect of interference: To study the selectivity of the proposed method, the effect of foreign species on the determination of $1.5 \mu \mathrm{g} \mathrm{mL} \mathrm{m}^{-1} \mathrm{Mn}(\mathrm{VII})$ was tested. When the

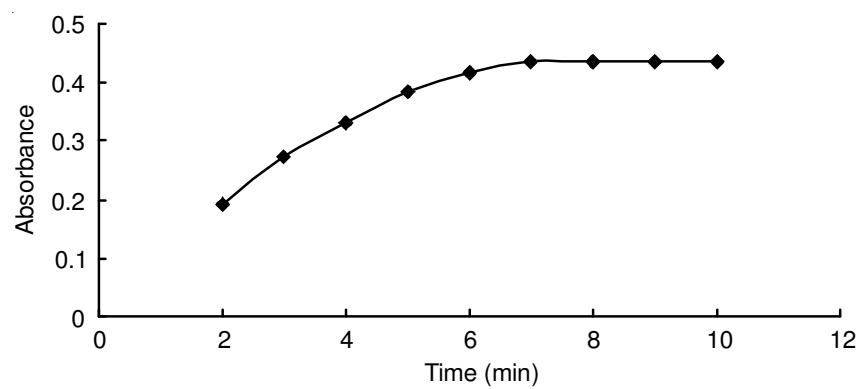

Fig. 4. Effect of reaction time: $15 \mathrm{mg} \cdot \mathrm{L}^{-1}$ acid fuchsin, $1.0 \mu \mathrm{g} \cdot \mathrm{mL}^{-1} \mathrm{Mn}(\mathrm{VII})$, $0.03 \mathrm{~mol} \cdot \mathrm{L}^{-1} \mathrm{H}_{2} \mathrm{SO}_{4}$

relative error is within $\pm 5 \%$, the allowable amounts of foreign ions are shown in Table-1.

\begin{tabular}{lc}
\multicolumn{2}{c}{ TABLE-1 } \\
EFFECT OF FOREIGN IONS \\
\hline \multicolumn{1}{c}{ Foreign ions } & Allowable amount $\left(\mathrm{mg} \mathrm{mL}^{-1}\right)$ \\
\hline $\mathrm{Na}^{+}, \mathrm{K}^{+}, \mathrm{NH}_{4}^{+}, \mathrm{Ag}^{+}$ & 0.5 \\
$\mathrm{Mg}^{2+}, \mathrm{Al}^{3+}, \mathrm{Ca}^{2+}, \mathrm{Co}^{2+}, \mathrm{Ni}^{2+}, \mathrm{Fe}^{2+}$ & 5.0 \\
$\mathrm{Cr}^{3+}$ & 2.0 \\
$\mathrm{Cl}^{-}, \mathrm{SO}_{4}^{2-}, \mathrm{NO}_{3}^{-}$ & 3.0 \\
\hline
\end{tabular}

Working curve: A series of Mn(VII) standard solutions with different concentration were prepared and the absorbance of these solutions were measured. The working curve is shown in Fig. 5. The results show that Beer's law is obeyed in the range of $0-1.5 \mu \mathrm{g} \mathrm{mL} \mathrm{m}^{-1}$ for $\mathrm{Mn}(\mathrm{VII})$. The linear regression equation was $\mathrm{A}=0.0458 \mathrm{C}-0.0034$ with the regression coefficient $\gamma=0.9993$.

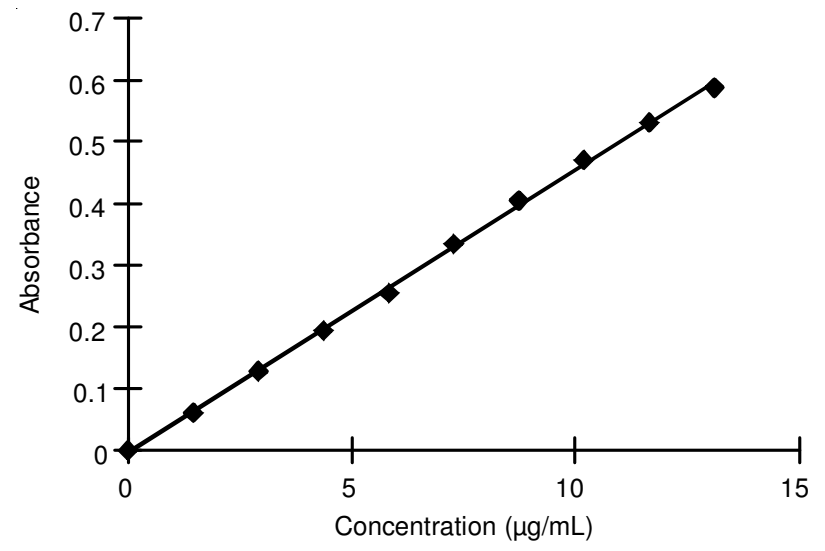

Fig. 5. Working curve: $15 \mathrm{mg} \mathrm{L}^{-1}$ acid fuchsin, $0.03 \mathrm{~mol} \mathrm{~L}^{-1} \mathrm{H}_{2} \mathrm{SO}_{4}$

Application: To investigate the application of the proposed method, it was applied to the determination of total manganese in several kinds of wine. $2.0 \mathrm{~mL}$ of sample solution was transferred to a $10 \mathrm{~mL}$ colorimetric tube and then $1.5 \mathrm{~mL}$ of $1.0 \mathrm{~mol} \mathrm{~L}^{-1} \mathrm{H}_{2} \mathrm{SO}_{4}$ and $1.5 \mathrm{~mL}$ of $1.0 \mathrm{~mol} \mathrm{~L}^{-1} \mathrm{H}_{3} \mathrm{PO}_{4}$ were added. After diluted the solution to $c a .8 \mathrm{~mL}, 5.0 \mathrm{~g}$ of sodium bismuthate was added and heated in boiling water bath for 10 min to oxidate $\mathrm{Mn}$ (II) to $\mathrm{Mn}$ (VII). The cooling solution was filtered and filtrate was used to analysis by this method and atomic absorption spectrometry. The standard addition recovery experiments were also made. The analysis results were shown in Table-2. 
TABLE-2

ANALYTICAL RESULTS OF SAMPLES AND RECOVERY $(\mathrm{n}=7)$

\begin{tabular}{|c|c|c|c|c|c|c|c|}
\hline \multirow{2}{*}{ Sample } & \multirow{2}{*}{ Found $(\mu \mathrm{g})$} & \multirow{2}{*}{$\operatorname{RSD}(\%)$} & \multicolumn{2}{|c|}{ Manganese concentration in sample (mg/L) } & \multirow{2}{*}{ Added $(\mu \mathrm{g})$} & \multirow{2}{*}{ Recoved $(\mu \mathrm{g})$} & \multirow{2}{*}{ Recovery $(\%)$} \\
\hline & & & This method & AAS & & & \\
\hline Beer 1 & 1.37 & 2.12 & 0.69 & 0.68 & 1.50 & 1.48 & 98.7 \\
\hline Beer 2 & 1.64 & 1.43 & 0.82 & 0.84 & 1.50 & 1.53 & 102.0 \\
\hline Liquor 1 & 1.01 & 1.87 & 0.51 & 0.53 & 1.00 & 0.98 & 98.0 \\
\hline Liquor 2 & 2.12 & 0.98 & 1.06 & 1.03 & 2.00 & 1.99 & 99.5 \\
\hline Grape wine 1 & 0.85 & 1.52 & 0.43 & 0.47 & 1.00 & 1.01 & 101.0 \\
\hline Grape wine 2 & 0.52 & 2.10 & 0.26 & 0.25 & 1.50 & 1.51 & 100.7 \\
\hline
\end{tabular}

\section{Conclusion}

A spectrophotometric method for the determination of manganese based on the oxidability of $\mathrm{Mn}(\mathrm{VII})$ was developed. The method was used for the determination of manganese in several kinds of wine. The results show that the method is easy, rapid and inexpensive.

\section{REFERENCES}

1. L. Quintanar, Inorg. Chim. Acta, 361, 875 (2008).

2. A.L. Valfredo and T.D. Graciete, Microchem. J., 94, 42 (2010).
3. H. Bilinski, Z. Kwokal and M. Branica, Water Res., 30, 495 (1996).

4. C.E. Banks, J. Kruusma, R.R. Moore, P. Tomcík, J. Peters, J. Davis, Š. Komorsky-Lovric and R.G. Compton, Talanta, 65, 423 (2005).

5. J.W. Di and F. Zhang, Talanta, 60, 31 (2003).

6. J.L. Manzoori, M. Amjadi and J. Abulhassani, Talanta, 77, 1539 (2009).

7. L.M. Jamshid, A. Mohammad and A. Jafar, J. Food Compos. Anal., 77, 1539 (2009).

8. D. Kostvoa, J. Anal. Chem., 65, 159 (2010).

9. B. Rezaei, J. Anal. Chem., 61, 1074 (2006).

10. K.L. Mutaftchiev, Chem. Pap., 60, 279 (2006). 